\title{
CHARACTERIZATION OF AL-GRAPHITE COMPOSITE DEVELOPED BY POWDER METALLURGY TECHNIQUE
}

\author{
Aravind Appanna K E $\mathbf{1}^{1}$, K. S Keerthiprasad ${ }^{2}$ \\ ${ }^{1}$ M-Tech Student, Department of Mechanical Engineering, Vidya Vikas Institute of Engineering and Technology, \\ Mysuru, Karnataka, Iindia \\ ${ }^{2}$ Professor and Head, Department of Mechanical Engineering, Vidya Vikas Institute of Engineering and Technology, \\ Mysuru, Karnataka, Iindia \\ apannarvind@gmail.com
}

\begin{abstract}
The applications of the composite material have grown steadily and which occupy the new market. The main reason for using the composite is to reduce the weight. Aluminium has a wide advantage in research field which is used as base metal in many MMC's. In this experimental study, Aluminium graphite MMCs was fabricated by mixing of graphite powder into aluminium powder followed by powder metallurgy route. The composite were compacted and sintering was done at $450^{\circ} \mathrm{C}$. It has been found that addition of graphite into aluminium does not result in much improvement in hardness due to the soft nature of graphite.
\end{abstract}

Key Words: Aluminium, Graphite, Powder metallurgy, Microstructure.

\section{INTRODUCTION}

Powder metallurgy is defined as mixing different metal powders to form finished and semi-finished components by compressing it. After compressing material is subjected to heating at elevated temperature in a furnace under a progressive atmosphere is done, so as to obtain satisfactory strength, density without losing essential shape. The powder metallurgy technique involves four major steps: Powder manufacture, Powder blending, Compacting, and Sintering. The matrix material and the reinforcement material used in this process of powder metallurgy are aluminium and graphite which is of very fine powder form. The powder used that is aluminium and graphite materials are mixed properly through powder blending process with the help of lathe chuck, hand or ball milling equipment. Once the powder are mixed thoroughly it is then transferred to the mould cavity where it is then compressed at a pressure of $45 \mathrm{knN}$. In the UTM the blended powder is compressed gradually until $45 \mathrm{kN}$ is achieved. Then the compacted specimen is sintered in order to achieve higher strength in the heat treatment oven, temperature of $450^{\circ} \mathrm{C}$ is maintained the specimen has to be placed in the oven for about 7 to 8 hours. The specimen is then done with testing in order to know the mechanical properties.

\section{EXPERIMENTAL DETAILS}

\subsection{Materials Used}

Aluminium is a lightweight, bright silver luster metallic element. It is $3^{\text {rd }}$ most abundant element occurring in $8.3 \%$ of the earth's crust.

Aluminium is a very good conductor of heat and electricity and a good reflector too. It is soft, non-magnetic metal can be cast, extruded, rolled and wrought into many shapes. Its strength can be adapted to the application required by modifying the composition of its alloys. It is particularly useful for applications where protection and conservation are required. Aluminium is $100 \%$ recyclable with no downgrading of its qualities. The re-melting of aluminium requires little energy.

(b). Graphite is a crystalline form of carbon, a semimetal. Graphite is the most stable form of carbon under standard condition. With its unique structure and different properties, graphite is a versatile raw material used in many industries.

The compaction of Aluminium powder with iron oxide was completed in a universal testing machine. Aluminium powder and varying percentage of graphite reinforcement is introduced in the die cavity and made compacted. Pressing by a punch of applied loads of $40-45 \mathrm{kN}$.

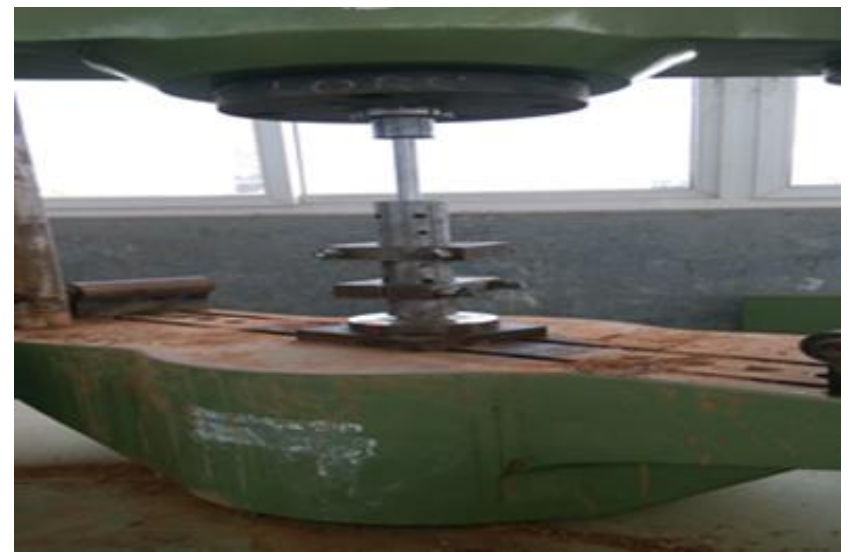

Fig 1: Compaction Process

The developed compacted parts were later shifted into a sintering furnace to carryout sintering operation. The compacted specimens were cooled in the furnace till it attained room temperature. 


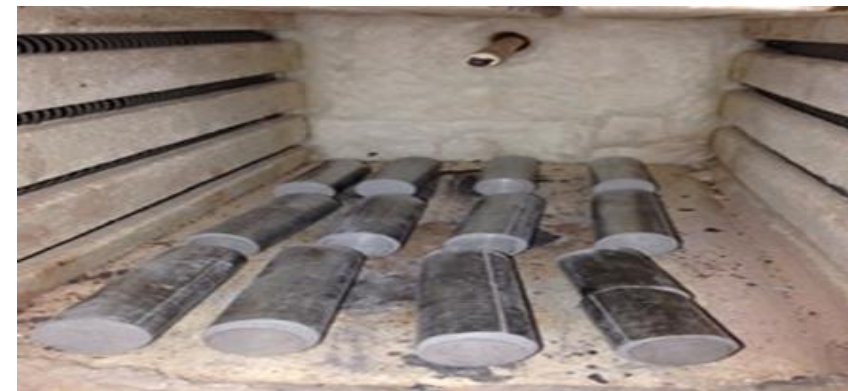

Fig 2: Sintering Process

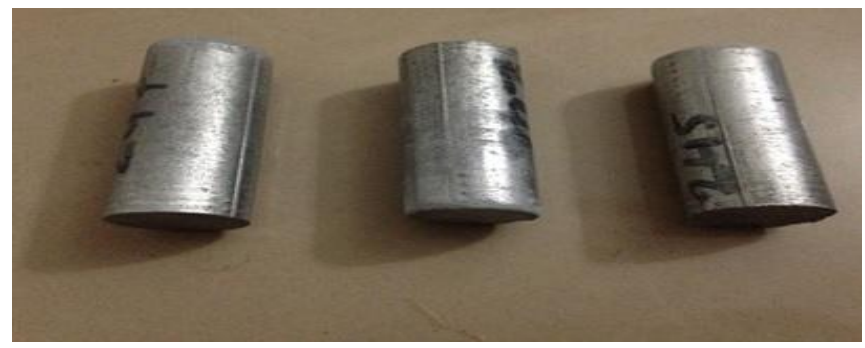

Fig 3: Specimens

Table 1: Table shows the designation of reinforced with aluminium

\begin{tabular}{|l|l|l|}
\hline SI. No. & $\begin{array}{l}\text { COMPOSITE } \\
\text { (A-Aluminium) }\end{array}$ & $\begin{array}{l}\text { REINFORCEMENT } \\
\text { (Wt } \%)\end{array}$ \\
\hline 1. & A-4G & $4 \%$ of graphite $(\mathrm{G})$ \\
\hline 2. & A-6G & $6 \%$ of graphite \\
\hline 3. & A-8G & $8 \%$ of graphite \\
\hline
\end{tabular}

\subsection{Fabrication of Die \& Punch}

To form a solid component from powder mixture a very important consideration is to design die and punch such that the die sustained circumferential stress and longitudinal stress without failure and punch is design to keep consideration of buckling failure if the length of punch is more buckle failure will happened when load is applied. Base is design to keep the complete assembly of die and punch with minimum clearance for stable the whole assembly when load is applied.

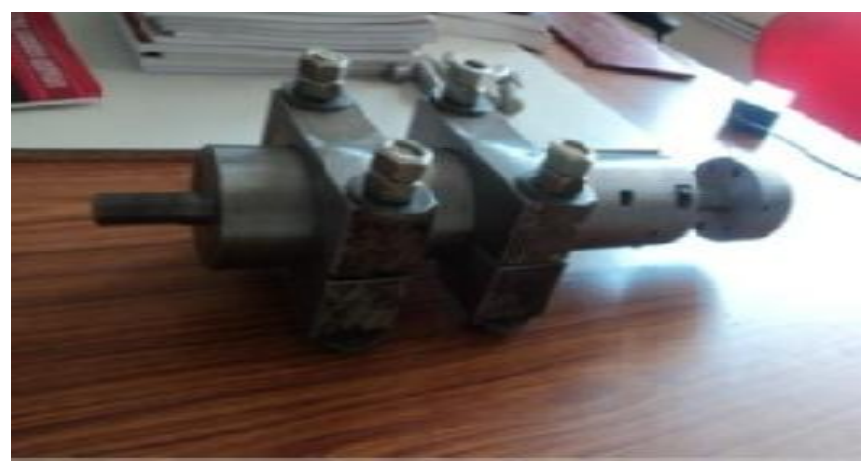

Fig 4: Die and Punch assembly

\section{3: Blending, Compaction and sintering}

The powder of any material is mixed by many processes like by hand, by ball milling machine and by continuous mixing using the chuck of a lathe. If the mixing of the powder is proper then the properties of the composite material are enhanced. In this experiment, the powder of aluminium and graphite are mixed by using the chuck of lathe.

\section{RESULTS \& DISCUSSION}

\subsection{Microstructure}

Microstructure specimens were prepared as per standard metallurgical procedures, etched in etchant prepared using $90 \mathrm{ml}$ water, $4 \mathrm{ml} \mathrm{HF}, 4 \mathrm{ml} \mathrm{H}_{2} \mathrm{SO}_{4}$ and $2 \mathrm{~g} \mathrm{C}_{\mathrm{r}} \mathrm{O}_{3}$ and photographed using Optical Microscope.

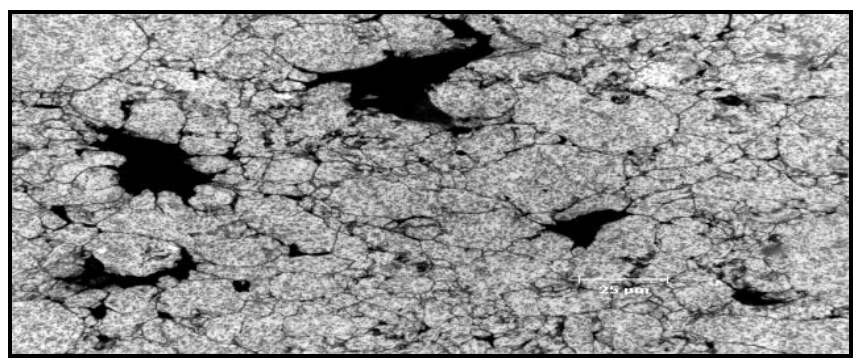

Fig 5: Microstructure of 4\% graphite

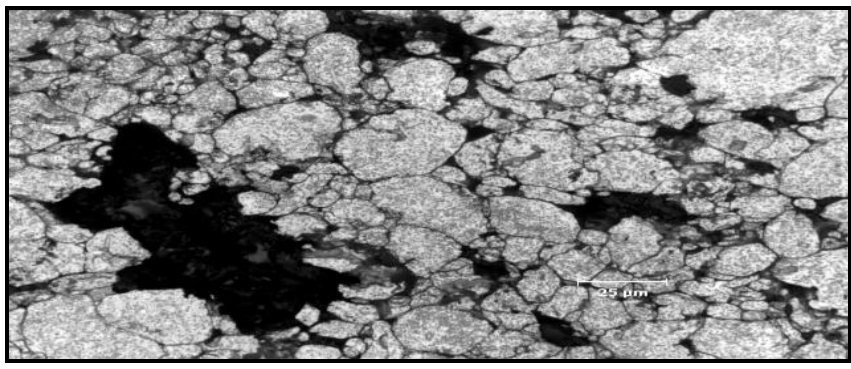

Fig 6: Microstructure of 6\% graphite

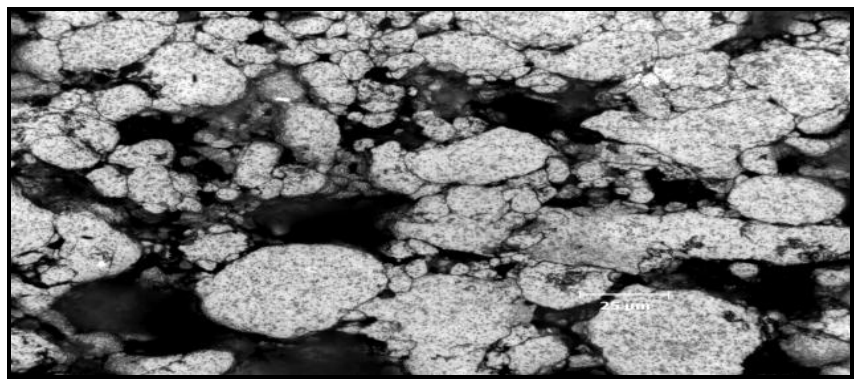

Fig 7: Microstructure of $8 \%$ graphite

Microstructure consists of fine precipitates of alloying elements dispersed in the matrix of aluminium with uniform distribution of graphite.

\subsection{Hardness test}

Hardness test were conducted for aluminium and graphite reinforced at different percentage.

Table 2: Vickers hardness number (VHN) of aluminium reinforced with graphite.

\begin{tabular}{|l|l|l|}
\hline SI No. & Material & VHN \\
\hline 1. & A-4G & 24.0 \\
\hline 2. & A-6G & 25.0 \\
\hline 3. & A-8G & 22.7 \\
\hline
\end{tabular}




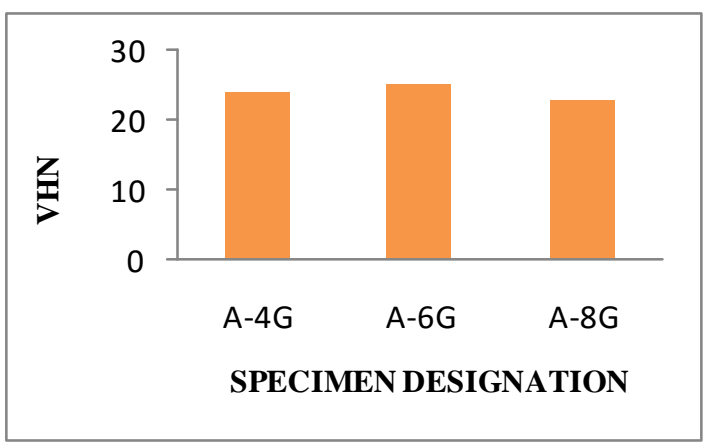

Fig 8: Chart showing VHN of aluminium reinforced with graphite.

\subsection{Compression Test}

Compression test were conducted for aluminium and graphite reinforced at different percentage.

Table 3: Table shows the compression strength of aluminium reinforced with graphite.

\begin{tabular}{|l|l|l|l|}
\hline SI NO. & Material & $\begin{array}{l}\text { Compression } \\
\text { strength, } \\
(\mathrm{MPa})\end{array}$ & $\begin{array}{l}\text { Peak load } \\
(\mathrm{kN})\end{array}$ \\
\hline 1. & A-4G & 49.52 & 15.56 \\
\hline 2. & A-6G & 26.61 & 8.36 \\
\hline 3. & A-8G & 38.06 & 11.96 \\
\hline
\end{tabular}

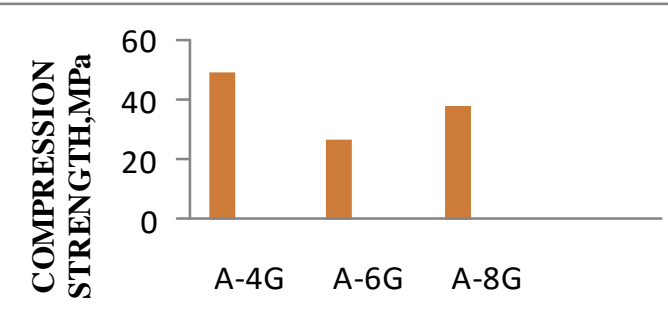

SPECIMEN DESIGNATION

Fig 9: Chart showing compression strength of aluminium reinforced with graphite.

\section{CONCLUSIONS}

In the present experimental study, the aluminium graphite MMCs was fabricated by mixing 4, 6, 8\% of graphite powder into aluminium powder followed by powder metallurgy technique. The powder was blended thoroughly and it was subjected to compaction process and sintering was done at $450^{\circ} \mathrm{C}$. It has been found that addition of graphite into aluminium does not result in much improvement in hardness due to the soft nature of graphite. Microstructure indicates fine precipitates of aluminium with $\mathrm{u}$ niform distribution of graphite and coconut shell ash.

The hardness increases with increased graphite content up to $6 \%$ of graphite. Beyond $6 \%$ a decreased hardness is observed which may be attributed to saturation of graphite in the aluminium matrix.

The Value of hardness decreased with addition of coconut shell ash beyond which it decreases indicating that the optimised reinforcement can be restricted to $4 \%$.
The highest compression strength is achieved at reinforcement of $4 \%$ of graphite. The highest compression strength is achieved at reinforcement of $6 \%$ of coconut shell ash.

\section{ACKNOWLEDGEMENT}

I am thankful to the guide Dr. Keerthiprasad K.S, professor and Head of the Department of Mechanical Engineering, VVIET, Mysore, for their guidance and advice during the course of this work.

I am extremely thankful to Dr. Shriram N.S, Dean \& professor of Department of Mechanical Engineering, VVIET, Mysore and Dr. Ravishankar, Principal, VVIET, Mysore, for the facilities made available at the college for carrying out this thesis work successfully.

I take this opportunity to express my profound sense of gratitude to our Institution, Vidya Vikas Institute of Engineering \& Technology, Mysore. This has provided an opportunity in fulfilling the most cherished dream.

\section{REFERENCES}

1. R.V. Ramanujan, Y.R. Zhang, Microstructural observations of the crystallization of amorphous $\mathrm{Fe}$ Si-B based magnetic alloys, Thin Solid Film 505 (2006) 97-118.

2. Makino, T. Bitoh, Magnetic properties of zero magnetostrictive nano crystalline $\mathrm{Fe}-\mathrm{Zr}-\mathrm{Nb}-\mathrm{B}$ soft magnetic alloys with high magnetic induction, Journal of Magnetism and Magnetic Materials 215-216 (2000) 288-295.

3. Olszówka-Myalska, J. Szala,J. Cwajna, Characterization of iron aluminides formed in situ in an aluminium matrix composite, Materials Characterization 56 (2006) 379-383.

4. Dr. Richard B. Griffin et al. have done an experiment

5. W. Pilarczyk, R. Nowosielski, M. Nowak, M. Kciuk, The structural changes of Al-Ti-Fe alloy during mechanical alloying process, Journal of Achievements in Materials and Manufacturing Engineering 29/2 (2008) 131-138.

6. L.A. DobrzaEski, K. Labisz. A. Olsen, Microstructure and mechanical properties of the Al-Ti alloy with calcium addition, Journal of Achievements in Materials and Manufacturing Engineering 26/2 (2008) 183-186.

7. J. Szajnar, T. Wrobel, Inoculation of primary structure of pure aluminium, Journal of Achievements in Materials and Manufacturing Engineering 20 (2007) 283-286.

8. T. Lipinski, Improvement of mechanical properties of AlSi7Mg alloy with fast cooling homogenous modifier, Archives of Foundry Engineering 8 (2008) 85-88.

9. G. Mrowka-Nowotnik,J. Sieniawski, M. Wirzbinska, Intermetallic phase particles in 6082 aluminium alloy, Archives of Materials Science and Engineering 28/1 (2007) 69-76.

10. D. Kuc, G. Niewielski, M. Jablonska,I. Bednarczyk, Deformability and Recrystallisation of $\mathrm{Fe}-\mathrm{Al}$ Intermetallic, Phase-Base Alloy, Journal of Achievements in Materials, and Manufacturing Engineering 17 (2006) $107-110$. 